|| ISSN(online): 2589-8698 || ISSN(print): 2589-868X ||

International Journal of Medical and Biomedical Studies Available Online at www.ijmbs.info

NLM (National Library of Medicine ID: 101738825)

Index Copernicus Value 2019: 79.34

Original Research Article

Volume 5, Issue 9; September: 2021; Page No.157-159

THE FREQUENCY OF HYPONATREMIA AND HYPOKALEMIA IN MALNOURISHED CHILDREN WITH ACUTE DIARRHEA

\author{
Dr. Sushil Kumar Bakolia ${ }^{1}$, Dr. Gajendra Kumar Verma ${ }^{2}$, Dr. Dinesh Kumar Barolia ${ }^{3}$ \\ ${ }^{1} \mathrm{MD}$ (Paediatrics), Assistant Professor, Govt. S.K. Medical College \& AG Hospital, Sikar (Rajasthan) \\ ${ }^{2} \mathrm{MD}$ (Paediatrics), Senior Resident, SMS Mc, Jaipur \\ ${ }^{3} \mathrm{M}$ Ch (Peadiatric Surgery, Assistant Professor, J L N Mc, Ajmer
}

Article Info: Received 05 August 2021; Accepted 17 September 2021

DOI: https://doi.org/10.32553/ijmbs.v5i9.2206

Corresponding author: Dr Dinesh Kumar Barolia

Conflict of interest: No conflict of interest.

\begin{abstract}
Background: Malnutrition is a major global health problem, with the major burden being in South Asia and Sub-Saharan Afric. The study was undertaken to determine the frequency of hyponatremia an hypokalemia in malnourished children with acute diarrhea.

Methods: Hospital based prospective study was conducted on 100 children between the age group of 6months to 5years presenting with acute diarrhea was include in the study.

Results: Hyponatremia was observed in total $15(15.00 \%)$ cases of diarrhea. Regarding the grade of malnutrition, hyponatremia was observed in only $4.44 \%$ in grade $1,8.69 \%$ in grade, $41.67 \%$ in grade 3 and $60.00 \%$ in grade 4 malnutrition respectively. Hypokalemia was noticed in $10.00 \%$ cases (10 out of 100 ) with acute diarrhea. The frequency of hypokalemia was $4.44 \%$ in grade $1,8.69 \%$ in grade $2,25.00 \%$ in grade 3 and $40.00 \%$ in grade 4 malnutrition respectively.

Conclusion: Electrolyte disturbances are often subclinical in malnourished children, but become obvious during the episode of acute diarrhoeal disease. Hence serum electrolytes of every malnourished child with acute diarrhoea should be estimated in order to do immediate correction and avoid serious life-threatening outcome.
\end{abstract}

Keywords: IAP, Malnutrition, Diarrhoea

\title{
Introduction
}

Malnutrition is a major global health problem, with the major burden being in South Asia and Sub-Saharan Afric. ${ }^{1}$

Many metabolic and electrolyte abnormalities are common in malnourished children which become more marked if accompanied by diarrhea. Severe malnutrition accounts for 2 million deaths annually with diarrhea being the most common complication. ${ }^{2}$

The prevalence of diarrhoea is 5-7 times more in malnourished as compared to normal children and its severity is 3 to 4 times greater in malnourished children as compared to normal children. ${ }^{3}$

Among various electrolyte abnormalities observed in malnourished children, the sodium $(\mathrm{Na})$ and potassium $(\mathrm{K})$ abnormalities are commonest. Total body potassium is decreased in all malnourished children, due to decreased intake and poor muscle mass. The serum sodium is reduced in most children with malnutrition masking the sodium overload due to sodium retention. The association of diarrhea is known to worsen these abnormalities in malnourished children. ${ }^{4}$ Hence early correction of hyponatremia and hypokalemia in malnourished patients with diarrhea can significantly reduce the mortality and morbidity. The study was undertaken to determine the frequency of hyponatremia an hypokalemia in malnourished children with acute diarrhea.

Material and Methods

Study design: Hospital based prospective study

Study population:

All the children between the age group of 6months to 5years presenting with acute diarrhea was include in the study

Sampling Method: Simple random sampling

Inclusion Criteria:

All the children between the age group of 6months to 5years presenting with acute diarrhea was included in the study

Exclusion Criteria:

Children under 6months or above 5years,

Children suffering from chronic renal disease, cystic fibrosis, cardiac diseases, chronic diarrhea and those receiving diuretics was exclude from study.

\section{Data Collection:}

A detailed history was obtained from parents. A thorough physical examination as done to assess the grade of dehydration. Anthropometric measurements such as weight, height, headcircumference and mid arm circumference was taken. Their nutritional status was graded as per Indian Academy of Pediatrics (IAP) classification using weight for 
age as the reference. The blood sample was drawn for serum electrolytes under aseptic measures and were sent to laboratory

\section{Results}

Hyponatremia was observed in total $15(15.00 \%)$ cases of diarrhea. Regarding the grade of malnutrition, hyponatremia was observed in only $4.44 \%$ in grade $1,8.69 \%$ in grade,
$41.67 \%$ in grade 3 and $60.00 \%$ in grade 4 malnutrition respectively. Hypokalemia was noticed in $10.00 \%$ cases $(10$ out of 100) with acute diarrhea. The frequency of hypokalemia was $4.44 \%$ in grade $1,8.69 \%$ in grade 2 , $25.00 \%$ in grade 3 and $40.00 \%$ in grade 4 malnutrition respectively.

Table 1: Hyponatremia and hypokalemia in relation to nutritional status

\begin{tabular}{|l|l|l|l|l|}
\hline $\begin{array}{l}\text { Malnutrition grade } \\
\text { (As per IAP) }\end{array}$ & Weight for age & No of total children & Hyponatremia present & Hypokalemia present \\
\hline Grade 1 & $71-80 \%$ & 45 & $2(4.44 \%)$ & $2(4.44 \%)$ \\
\hline Grade 2 & $61-70 \%$ & 23 & $2(8.69 \%)$ & $2(8.69 \%)$ \\
\hline Grade 3 & $51-60 \%$ & 12 & $5(41.67 \%)$ & $3(25.00 \%)$ \\
\hline Grade 4 & $<50 \%$ & 10 & $6(60.00 \%)$ & $3(40.00 \%)$ \\
\hline Total & & 100 & $15(15.00 \%)$ & $10(10.00 \%)$ \\
\hline
\end{tabular}

\section{Discussion}

Diarrhoea and malnutrition are serious health problemsin the children of developing countries. Fatality rate in a case of diarrhea increases when superimposed upon malnutrition. Various studies have shown that malnutrition is associated with increased incidence and duration of acute diarrhoea. It is also a risk factor for acute diarrhoea and respiratory mortality. ${ }^{6-12}$

A study conducted by Sameen I etal showed that diarrhoea (50.\%) was the most common infection and hyponatremia $(22.6 \%)$ the most common electrolyte abnormality in severely malnourished patients. ${ }^{13}$ only one case of diarrhoea without malnutrition had hyponatremia and the percentage of hyponatremia increased with the grade of malnutrition. Hyponatremia was noticed in 50\% cases with Grade 111 and $66.6 \%$ cases of grade1V malnutrition having diarrhoea. 13

Similar observations were made by Samadi AR and Memon $\mathrm{Y}$ etal. They also observed direct relation of hyponatremia to the degree of malnutrition. ${ }^{14,15}$ In our study none of the patients had hypernatremia. Memon et al. found hypernatraemia in $1.5 \%$ cases with acute gastroenteritis and malnutrition. Hypernatraemia could be due to inadequate free water intake by the patients or increased intake of sodium through improperly prepared oral rehydration solution. Hypernatremia in association with malnutrition and diarrhoea is associated with risk of neurological damage and high mortality ${ }^{14}$

\section{Conclusion}

Electrolyte disturbances are often subclinical in malnourished children, but become obvious during the episode of acute diarrhoeal disease. Hence serum electrolytes of every malnourished child with acute diarrhoea should be estimated in order to do immediate correction and avoid serious life-threatening outcome.

\section{References}

1. UNICEF WHO. Child growth standard and the identification of severe acute malnutrition in infants and children. Geneva: WHO; 2009

2. Mesham AR, Chatterjee M. Wasting away: The crises of malnutrition in India. Washington DC. The World Bank 1999.

3. Mubarak A, Atta-ullah M, Abid H. Acute hypokalemic flaccid paralysis in malnourished children. Pak Pead J 2003;27(4):166.

4. Jospe N, Forbes G. Fluid and electrolytes clinical aspect. Pediatric Rev 1996;17(11):395-403

5. Koli C S, Bhat M, Joshi S. The frequency of hyponatremia and hypokalemia in malnourished children with acute diarrhea. PARIPEX,2018;12(7):2122.

6. Scoharling JB, MCAuliffe JF, Desouza MA, Guerrant RL. Malnutrition is associated with increased diarrhoea incidence and duration among child in an urban Brazilian slum. Int Epidemol 1990;19(3):728-35.

7. Bairagi R, Chowdhury MK, Kim YJ. The association between malnutrition and diarrhea in rural Bangladesh. Int J Epidemiol 1987;16(3):447-81.

8. Bhutta ZA, Nizami SQ, Thbani S, Issani Z. Risk factor for mortality among hospitalized children with persistant diarrhea in Pakistan. J Trop Paedtr 1997;43(6):330-6.

9. Yoon PW, Black RE, Moulton LH. The effect of malnutrition on the risk of diarrhea and respiratory mortality in children $<22$ year of age in Cebu, Phillipines. Am J Clin Nutr 1997;65(4):1080-1.

10. Fagundes- Neto U, de Andrade JA. Acute diarrhoea and malnutrition: lethality risk in hospitalized infant. J Am Coll Nutr 1999;18(4):303-8.

11. Mahalanabis D, Alam AN, Rahman N, Hasnat A. Prognostic indicators \& risk factors, for increased duration of acute diarrhea and for persistent diarrhea in children. Int J Epidemiol 1991;20(4):1064-72. 
12. Shah RH, Javdekar BB. Management of children with severe acute malnutrition: experience of nutrition rehabilitation centre at Baroda, Gujarat. Int J Contemp Pediatr. 2014 May;1(1):3-6

13. Sameen I, Moorani KN. Morbidity patterns of severely malnourished children at tertiary care hospital. Pak Paed J 2014;38: 3-8.

14. Samadi AR, Waheed MA, Islam MR, Ahmed SM. Consequences of hyponatremia and hypernatremia in children with acute diarrhea in Bangladesh. Br Med J (Clin Res Ed).1983;26:286(6366):671-3.

15. Memon Y, Majeed R, Ghani MH, Shaikh S. Serum electrolyte changes malnourished children with diarrhea. Pak J Med Sci 2007; 23: 760-4. 18. Paul AC, Ranjini K, Muthulakshmi, Roy A, Kirubakaran C. Malnutrition and hypernatremia in breast fed babies. Ann Trop Pediatr 2000;20(3):179-83 